\title{
Cloud rats in the Philippines - preliminary report on distribution and status
}

\author{
W. L. R. Oliver, C. R. Cox, P. C. Gonzales and L. R. Heaney
}

This paper describes a preliminary field survey of bushy-tailed cloud rats Crateromys spp. and slender-tailed cloud rats Phloeomys in the Philippines in April and May 1990. Brief visits were made to all islands/locations known to support these animals and also to neighbouring areas considered likely to do so. Comparing the results with information from previous surveys suggests that both genera, particularly Crateromys, are more widely distributed than formerly believed, but that some forms are threatened. Three of the four known species of Crateromys are known only from their holotype specimens, one of which awaits description. Another is extinct in its type locality on Ilin Island but may survive on neighbouring Mindoro. These preliminary findings indicate that thorough surveys are required to establish the status of certain species, to investigate the possibility that new species remain undiscovered and to develop conservation plans to reduce the likelihood of further extinctions occurring.

\section{Introduction}

There are at least 22 genera and 52 species of murid rodents in the Philippines, of which 16 genera and 44 species are endemic (Heaney et al., 1987). Among the endemic genera are Phloeomys and Crateromys, the Philippine cloud rats, which are among the most spectacular and attractive rodents in the world. They present particular conservation problems in that they have restricted and, in the case of Crateromys spp., disjunct ranges, and there is a high probability of new taxa being discovered.

Both genera are known only from the eastern part of the Philippine archipelago (Figure 1). Two species of Phloeomys are recognized: the slender-tailed cloud rats, $P$. pallidus and $P$. cumingi on Luzon (the latter including the neighbouring islands of Catanduanes and Marinduque) (Heaney et al., 1991). Three species of bushy-tailed cloud rats Crateromys spp. have been described to date, while another, from Panay, awaits description. The three named species are $C$. schadenbergi from Luzon, C. paulus from Ilin Island off Mindoro and $C$. australis from Dinagat off north Mindanao.
The discovery of the Panay species means that the genus Crateromys is now known from widely separated locations in each of the four principal faunal regions or late Pleistocene islands (Luzon, Mindoron, Mindanoan and Negros) as defined by Heaney (1986) on the basis of the $120 \mathrm{~m}$ bathymetric line (Figure 1). It is therefore quite possible that additional populations or taxa of these animals could be discovered anywhere within this larger oceanic region (i.e. excluding Palawan and associated islands) of the Philippines.

Apart from their large size, cloud rats are externally distinguished from all other murid rodents by their densely furred tails, which in Crateromys spp. are long-haired and bushy. All species in both genera also have relatively long, dense body pelage, which is spectacularly coloured and patterned in some species (e.g. C. australis) and highly variable in others (e.g. C. schadenbergi and P. pallidus).

The ecology and behaviour of these animals remains extremely poorly known, although available information suggests that both species of Phloeomys are highly adaptable and able to persist in some seriously degraded habitats, including predominantly agricultural 
and pasture land, as long as sufficient cover remains. By comparison, Crateromys spp. appear to be far less tolerant of humaninduced changes in their forest habitats, this being almost certainly due to their more arboreal life-style.

Cloud rats live alone, in pairs, or in pairs with one or two dependent young, which are born in tree-holes or hollows well above ground level (Crateromys spp.), or in the hollow boles of standing or fallen trees or in holes in the ground (Phloeomys spp.). With the possible exception of $C$. australis on Dinagat Island they are widely, sometimes intensively, hunted by local people for food. Hunting methods vary from opportunistic captures while hunting for other animals with dogs and guns (e.g.
Panay), to directed hunts with trained dogs or snares placed at the entrances to their holes in trees or the ground. The number of animals killed by these means is impossible to estimate, but interviews with local people in 54 locations in Luzon in 1990 indicate that cloud rats of all three species on that island (but particularly $P$. pallidus and C. schadenbergi) are the most commonly hunted animals in many areas and hundreds are taken annually (Oliver and Cox, 1990).

These and other data on the distribution and conservation status of these animals were obtained during a preliminary survey in April and May 1990. It was based on interviews with approximately 200 tribal hunters and other people in about 80 lo-cations. It included

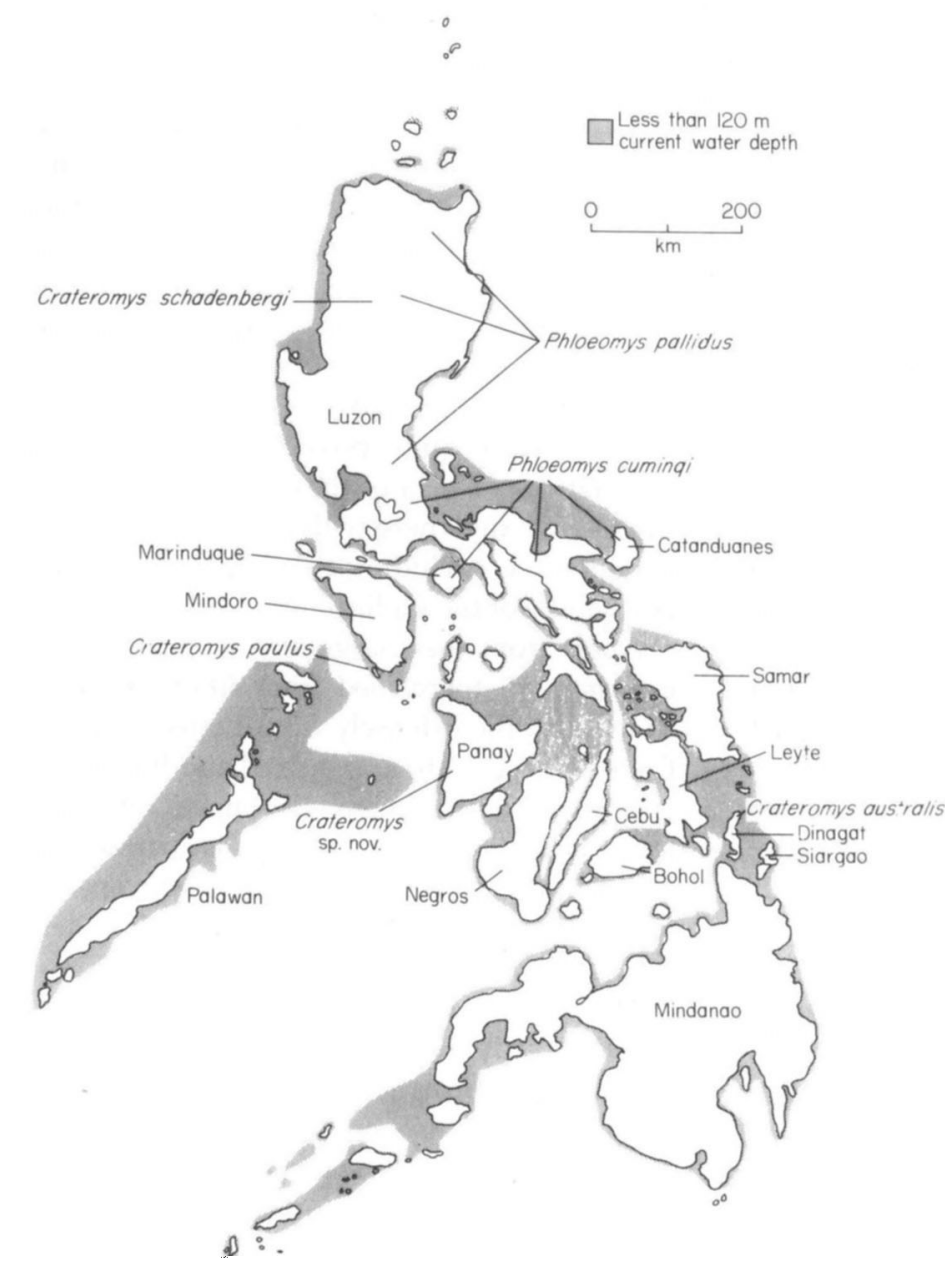

Figure 1. Current known distribution of the cloud rats Phloeomys spp. and Crateromys spp., in relation to the principal faunal regions/late Pleistocene islands of the Philippines, as defined by the $120-\mathrm{m}$ bathymetric line. (Modified after Heaney, 1986.) 
visits to all islands known or believed likely to support these species (Figures 2-6). The principal findings of this survey and from other recent faunal surveys (Heaney et al., 1991) are summarized below.

\section{Slender-tailed cloud rats Phloeomys spp.}

Phloeomys pallidus northern Luzon slendertailed cloud rat

This species has the largest range of any cloud rat, being discontinuously distributed through at least 12 provinces of Luzon north of Laguna
(Figure 2). It is reported to be locally abundant in some areas, despite continued, sometimes intense, hunting pressure (Oliver and Cox, 1990). It is evidently highly adaptable, because it occurs in a wide variety of habitat types from sea-level to at least $2000 \mathrm{~m}$, and it is reputed to persist in some seriously degraded or virtually denuded areas. There is no evidence that it should be considered threatened.

The pelage is variable, but typically predominately white with a distinct black mask and collar. Pure white specimens are also known and reported to be locally common in some places. Igorot hunters reported brown individuals, apparently of this species, in two
Figure 2. Confirmed and reported locations for the northern Luzon slender-tailed cloud rat Phloeomys pallidus and the southern Luzon slendertailed cloud rat $P$. cumingi. (Forest cover data modified after Forest Management Bureau, 1988; and by courtesy of the World Conservation Monitoring Centre.)

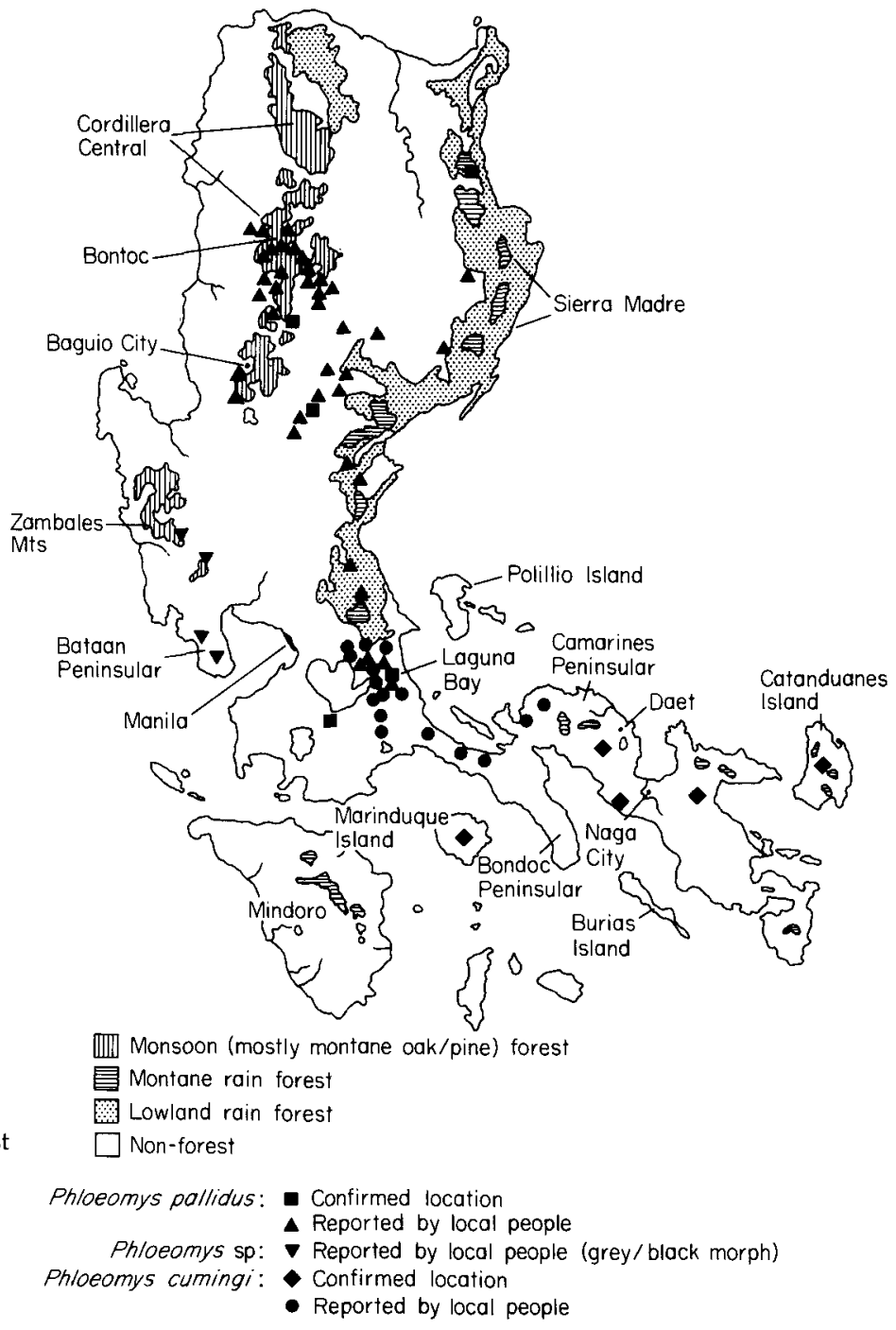


locations in south Mountain Province and Negrito hunters reported grey-black forms in the mountains of the Bataan and Zambales Provinces of western Luzon. Neither of these forms have been described previously and it would be necessary to acquire specimens to ascertain whether they are simply local colour variants or new taxa. Despite their proximity to Manila, faunal surveys have yet to be conducted in the Zambales Mountains or Bataan Peninsula, which are now isolated by urban and agricultural land. Most of the few remaining forest patches are badly degraded and most are certain to have been damaged by the eruption of Mount Pinatubo in 1991.

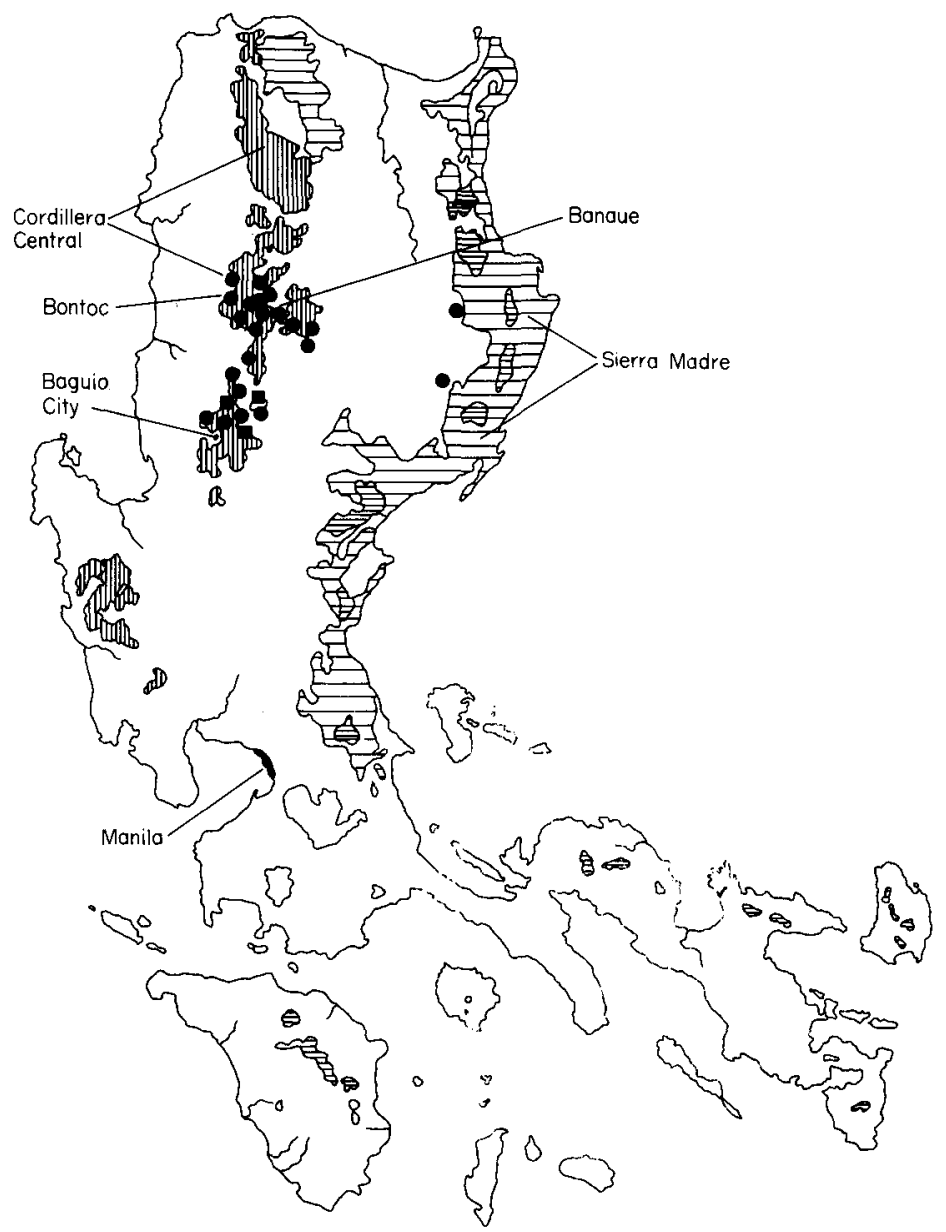

illil Monsoon (mostly montane oak/pine) fores $\dagger$

Montane rain forest

Lowland rain forest

$\square$ Non-forest
Phloeomys cumingi southern Luzon slendertailed cloud rat

This species has a patchy distribution in six provinces in southern Luzon and the islands of Catanduanes and Marinduque (Figure 2). It is known or reported to occur in all remaining forested areas in this region and appears able to persist in predominately agricultural areas despite sustained hunting pressure. In the north of its range, in Quezon Province, it was reported from several locations (mostly coconut plantations) close to sea-level and, in Mt Isarog National Park, from about $150 \mathrm{~m}$ (in
Figure 3. Confirmed and reported locations for the Luzon giant bushy-tailed cloud rat Crateromys schadenbergi. 
Figure 4. Confirmed and reported locations for Crateromys paulus on Ilin Island and Crateromys (?) sp. on Mindoro. (Forest cover data modified after Forest Management Bureau, 1988; and by courtesy of the World Conservation Monitoring Centre.)

Figure 5. Confirmed and reported locations for C. australis on Dinagat Island and Crateromys (?) sp. on Siargao Island. (Forest cover modified after Forest Management Bureau, 1988; and by courtesy of the World Conservation Monitoring Centre.)
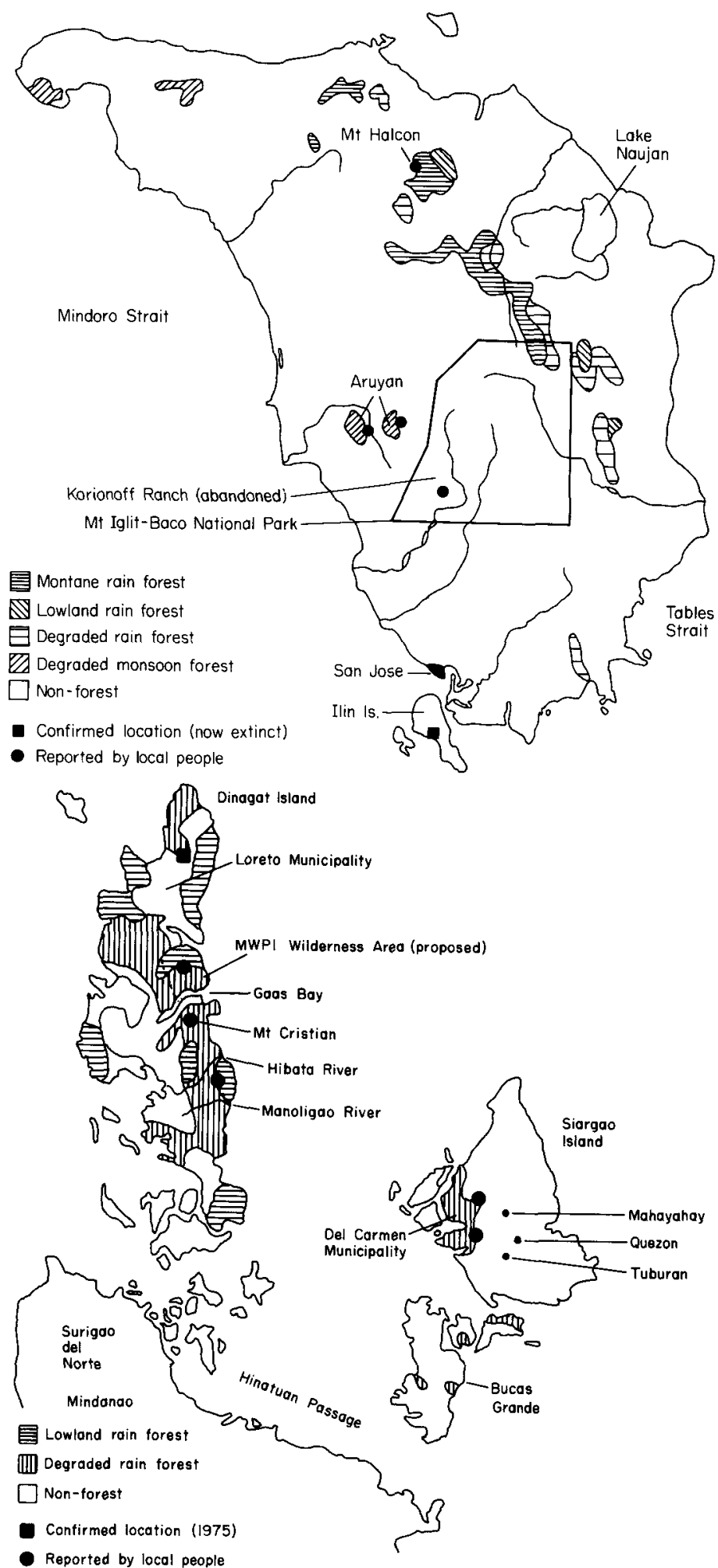
patches of degraded lowland forest) to about $900 \mathrm{~m}$ (the upper limit of lowland dipterocarp forest).

Informants in several parts of Quezon and the Camarines Provinces, including Mt Isarog, stated that the species was frequently captured and eaten, and some people claimed to catch up to 50 individuals a year. During a 2week faunal survey on Catanduanes Island in February 1988, hunters captured 13 animals in a hilly mosaic of degraded forest and agricultural land. These animals were located by dogs in hollow logs and trees and smoked out. Similar hunting methods are used elsewhere, although some hunters use snares and others shoot animals at night in coconut plantations (Oliver and Cox, 1990; Heaney et al., 1991).

Although it is doubtful whether this species is seriously threatened, it is far less secure than $P$. pallidus because of its more restricted and fragmented range and because deforestation is more extensive in southern Luzon. Further surveys are required in the Bondoc Peninsula and areas south of Daet and Naga city, which were not visited in 1990. While captive breeding might be considered necessary to safeguard this species and to investigate its life history, reproductive biology and behaviour, the overall conservation priority for the region rests with efforts to protect the largest remaining area of forest around $\mathrm{Mt}$ Isarog, in which all of the other southern Luzon endemic species of mammal are known or are likely to occur.

\section{Bushy-tailed cloud rats Crateromys spp.}

Crateromys schadenbergi Luzon or giant bushytailed cloud rat

This species, the largest and most widely distributed member of its genus, was believed to be confined to the southern section of the central highlands, the Cordillera Central, of northern Luzon, where Heaney et al. (1987) reported its status as: uncertain; apparently locally common in oak-pine forests, rare else-

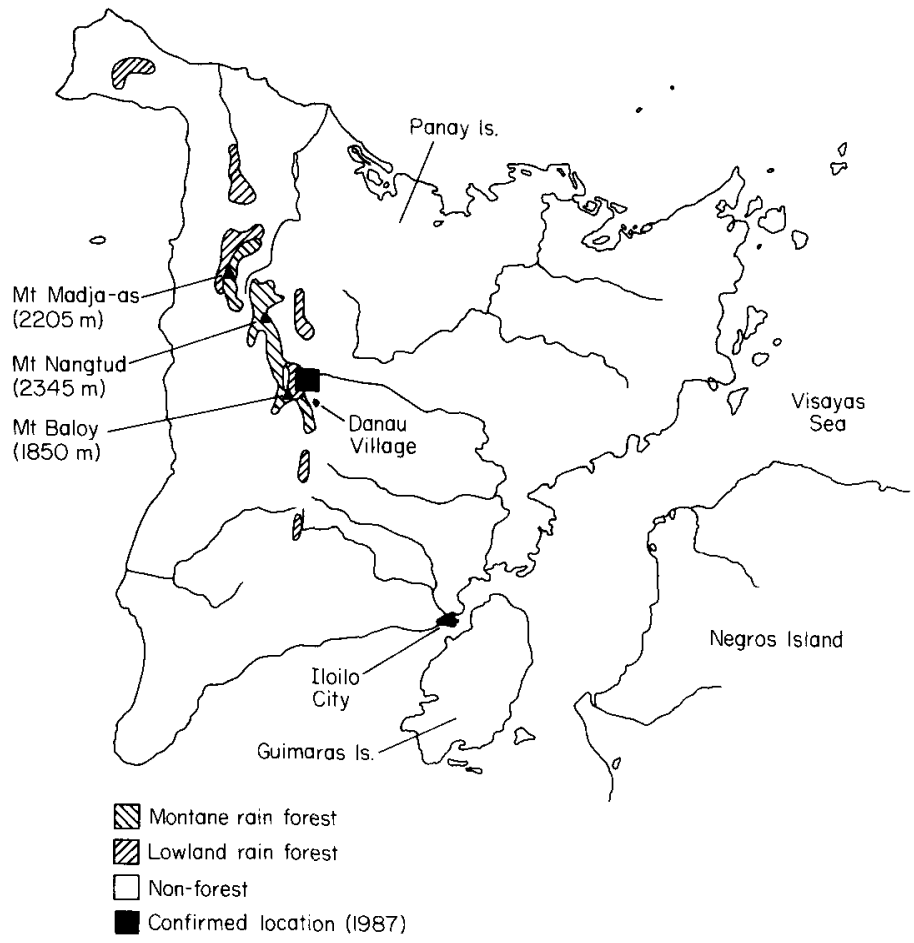

Figure 6. Approximate location of the undescribed Crateromys specimen from Panay Island. (Forest cover modified after Forest Management Bureau, 1988; and by courtesy of the World Conservation Monitoring Centre.) 
where. Fortunately the oak-pine forests are still relatively extensive. In 1988 forest cover was estimated at $2640 \mathrm{sq} \mathrm{km}$ in the provinces of Benguet, Ifugao and Mountain (Forest Management Bureau, 1988), where this species is known to occur, and a further $6220 \mathrm{sq} \mathrm{km}$ in Kalinga-Apayao Province, where the species probably occurs (Figure 3 ). The latter area was not investigated during the 1990 survey because of the presence of armed insurgents, although the first reports of its occurrence, or that of a closely related form, were obtained in the Sierra Madre. This region is very poorly known but has more remaining rain forest than any other area in the country.

Thus it appears that this species may have a somewhat larger range than some previous reports have suggested. It is predominantly arboreal, which probably explains reports that it has become scarce or has disappeared from seriously degraded and deforested areas. It is reported to be locally common, despite hunting pressure, in areas where sufficient forest cover remains. In areas north and south of Banaue, for example, Igorot hunters reported that it was the most frequently killed animal.

Priority recommendations for this species include the investigation of its possible occurrence in Kalinga-Apayao Province and other areas north of Bontoc in south Mountain Province, and to substantiate reports/obtain specimens of the bushy-tailed cloud rats in the Sierra Madre. The ecology and behaviour of the species remains almost entirely unknown and would merit investigation.

\section{Crateromys paulus Ilin Island bushy-tailed cloud rat}

This species is extinct in its type and only known locality on Ilin Island, south Mindoro (Figure 4). It is known only from the holotype specimen, an adult male collected in 1953 and described in 1981 (Musser and Gordon, 1981), by which time the island had been completely deforested for over 20 years (Pritchard, 1989). During the 1990 survey several reports were received of an animal of similar appearance to the $C$. paulus holotype on neighbouring Mindoro Island. Known to the local Batangan people as siyang, these animals are said to occur in remnant patches of lowland monsoon forest in the Aruyan area of west Mindoro and at the site of the former Korionoff Ranch in $\mathrm{Mt}$ Iglit-Baco National Park.

The immediate priority must be to verify the existence of the siyang and to obtain specimens for identification. Surveys are also needed in the vicinities of $\mathrm{Mt}$ Halcon and in remnant patches of montane or (mostly degraded) lowland rain forest in eastern Mindoro. They should also be undertaken with a view to the development of management recommendations for the enhanced future protection of the remaining lowland forests, which are being rapidly depleted.

\section{Crateromys australis Dinagat Island cloud rat}

This species is also known only from the holotype specimen, an adult male collected in 1975 and described in 1985 (Musser et al., 1985). Dinagat is still relatively well forested and local people reported that they do not hunt these animals. However, its very restricted range makes it of conservation concern.

During the 1990 survey people interviewed in three villages in the central part of the severely deforested neighbouring island of Siargao (Figure 5) reported an arboreal rat of similar appearance to the Dinagat cloud rat, which they referred to as hawili and which they said had become extremely scarce. A specimen of this animal should be obtained for identification at the earliest opportunity.

\section{A new species of Crateromys on Panay Island}

This, as yet undescribed, species is also known from only one adult male specimen. It was captured in a hollow tree in lowland monsoon forest in the vicinity of Mt Baloy during the course of a preliminary faunal survey of the proposed Panay Mountains National Park in west Panay in 1987 (Cox, 1987). Local people referred to it as kunehong gubat and reported that it occurs only in lowland monsoon forest. Unfortunately the few remaining patches of lowland forest are completely unprotected and seriously threatened by human encroach- 
ment. The species must be described as soon as possible and every effort should be made to protect the last remnants of lowland forest on Panay and to implement existing recommendations for the establishment of the proposed Panay Mountains National Park (Cox, 1987; Oliver et al., 1991). In the interim, the possibility of obtaining a small founder stock for captive breeding in an appropriately experienced breeding centre should be explored.

\section{Acknowledgments}

The 1990 field survey was funded by the Zoological Society of London, Parc Zoologique et Botanique de la Ville de Mulhouse and the Zoological Society of San Diego. The 1985 faunal survey of the proposed Panay Mountains National Park was funded by the Zoologischer Garten Berlin. The US National Science Foundation and the MacArthur Foundation provided generous support for various other faunal surveys, which have yielded data relevant to this report. For advice and diverse other assistance relating to these projects, the authors are indebted to $\mathrm{Dr}$ Celso Roque, Sammy Penafiel, Carlo Custodio, Dr Bobby Escalada, Edgar Canete, Marlynn Mendoza, Dr Domingo Madulid, Ruth Utzurrum, Eric Rickart, Boying Fernandez, Nema Taratan, Louella Dolar, Perla Magsalay, Stuart Pritchard, Dr Diana Bell, Roland Wirth, Dr Hans Frädrich, Alexandra Dixon, David Jones, Dr James Dolan and Dr Jean-Marc Lernould.

\section{References}

Cox, C.R. 1987. A Preliminary Survey of the Proposed Panay Mountains National Park. Unpubl. report to the Zoologischer Garten Berlin. 44 pp.

Forest Management Bureau, 1988. Natural Forest Resources of the Philippines. Philippine-German
Forest Resources Inventory Project, Forest Management Bureau, Department of the Environment and Natural Resources, Manila. $62 \mathrm{pp}$.

Heaney, L. R. 1986. Biogeography of mammals in South East Asia: estimates of rates of colonization, extinction and speciation. Biol. J. Linn. Soc. 28, 127-165.

Heaney, L.R., Gonzales, P.C. and Alcala, A.C. 1987. An annotated checklist of the taxonomic and conservation status of land mammals in the Philippines. Silliman J. 34 (1-4), 32-66.

Heaney, L.R., Gonzales, P.C., Utzurrum, R.C.B. and Rickart, E.A. 1991. The mammals of Catanduanes island: implications for the biogeography of small land-bridge islands in the Philippines. Proc. Biol. Soc. Wash. 104 (2), 399-415.

Musser, G.G. and Gordon, L.K. 1981. A new species of Crateromys (Muridae) from the Philippines. J. Mamm. 62 (3), 513-525.

Musser, G.G., Heaney, L.R. and Rabor, D.S. 1985. Philippine rats: a new species of Crateromys from Dinagat Island. Amer. Mus. Novitates, 2821, 1-25.

Oliver, W.L.R. and Cox, C.R. 1990. Distribution and Status of the Philippine Cloud Rats. Unpubl. report, $33 \mathrm{pp}$.

Oliver, W. L. R., Cox, C. R. and Dolar, L. 1991. The Philippine Spotted Deer Conservation Project. Oryx, 25, 199-205.

Pritchard, J.S. 1989. Ilin Island cloud rat extinct? Oryx, 23, 126.

William Oliver, 28A Eaton Road, Norwich, Norfolk NR4 6PZ, UK.

Roger Cox, 9 Markham Square, London SW3 4UY, UK.

Pedro Gonzales, Division of Zoology, National Museum of the Philippines, PO Box 2659, P. Burgos Street, Manila, Republic of the Philippines.

Lawrence Heaney, Division of Mammals, Field Museum of Natural History, Chicago, Illinois 60605-2496, USA. 